\title{
Long-Lived Larvae of the Gastropod Aplysia juliana: Do They Disperse and Metamorphose or Just Slowly Fade Away?
}

\author{
Stephen C. Kempf \\ Kewalo Marine Laboratory, 41 Ahui St., Honolulu, Hawaii 96813 , USA
}

\begin{abstract}
The planktonic larvae of the opisthobranch Aplysia juliana stop growing about $30 \mathrm{~d}$ after release from the egg mass. Both tissue and shell mass remain at a plateau in excess of $200 \mathrm{~d}$. During this period larvae swim, feed and reman competent to metamorphose. Mortality of larvae in long-term cultures appears to be due to environmental factors rather than senescence. The potential duration of larval life suggests that these larvae are capable of long-distance dispersal by major ocean currents.
\end{abstract}

\section{INTRODUCTION}

It has been proposed in the past that most benthic marine invertebrates produce larvae which have a planktonic period of relatively short duration, 3 to $6 \mathrm{wk}$ (Thorson, 1950, 1961; Ekman, 1953). The implication was that such larvae do not possess the potential. for trans-oceanic dispersal; transport of larvae away from coastal waters and into the open ocean was considered a large source of wastage and of little consequence in terms of species distribution. More recent studies suggest that larvae with the potential for long-distance dispersal are more common than previously thought (Scheltema, 1966, 1971b; Strathman, 1978). Scheltema (1966), in a series of plankton tows taken throughout the Gulf Stream and North Atlantic Drift, found a continuous distribution of prosobranch veliger larvae belonging to a species of the genus Cymatium. Subsequently, he provided examples of such teleplanic (farwandering) larvae from all the major invertebrate phyla (Scheltema, 1971b). Because larvae of Cymatium sp. taken at increasing distance from shore showed no mean increase in size, Scheltema (1966) proposed that teleplanic larvae attain a metabolic steady-state, assimilating enough nutrients to sustain swimming, feeding and other metabolic demands, but not enough to allow further growth. Despite the appeal of this hypothesis, substantial experimental proof for the existence of a metabolic steady-state during larval life with concomitant retention of metamorphic competence has not been forthcoming (Pechenik, 1980).

Hadfield (1963) considered certain opisthobranch veligers to be quite plastic in the length of their planktotrophic period and " able to metamorphose or continue to swim from soon after hatching to an extended period". This suggestion is supported by the fact that many opisthobranch species are known to produce larvae that will metamorphose only in response to a specific inducing substrate, usually the adult food (Thompson, 1958, 1962; Hadfield and Karlson, 1969; Kriegstein et al., 1974; Hadfield, 1977; Switzer-Dunlap and Hadfield, 1977; Chia and Rice, 1978). Veligers of a number of opisthobranchs have been shown to reach a plateau of shell growth just before the point in development when first able to metamorphose (Kriegstein et al., 1974; Switzer-Dunlap and Hadfield, 1977; Kempf and Willows, 1977; Chia and Koss, 1978); larvae of Rostanga pulchra can continue to feed and retain the ability to metamorphose for at least $3 \mathrm{wk}$ after competence to metamorphose is attained (Chia and Koss, 1978). These characteristics suggest that at least some opisthobranch larvae may maintain competence to metamorphose and a nongrowing steady-state long enough to accomplish tele- 
planic dispersal. The present report provides evidence for this hypothesis from laboratory experiments with larvae of Aplysia juliana.

\section{MATERIALS AND METHODS}

Egg masses were obtained from both laboratory reared and field-collected Aplysia juliana held in tanks with running sea water. The egg masses were incubated in aerated sea water previously filtered through a Millipore pre-filter (Cat. no. AP2504700). Water in cultures was changed daily until larvae emerged from the egg mass 7-8 d after oviposition. Larval cultures were set up to investigate (a) the length of the larval growth period, (b) persistence of the competence to metamorphose and (c) the ability of larvae to survive over long periods, Each culture initially consisted of 600 larvae in $800 \mathrm{ml}$ of Millipore prefiltered sea water. Cultures were fed the unicellular alga Pavlova (Monochrysis) lutheri and were maintained according to the methods of Switzer-Dunlap and Hadfield (1977). Temperatures during egg mass culture varied from $23.9^{\circ}-28.8^{\circ} \mathrm{C}$ and in larval cultures from $23.5^{\circ}-30.0^{\circ} \mathrm{C}$.

Data were collected from 2 sets of larval cultures during the investigation. Set I consisted of 3 larval cultures; 2 cultures from the same egg mass that were used to study growth (hereinafter termed growth cultures) and 1 additional culture from a different egg mass that was set up to determine the potential maximum duration of larval survival (hereinafter termed survival culture). Set II contained 15 larval cultures; 1 growth culture, 1 survival culture and 3 stock cultures were set up from each of 3 different egg masses (i. e. 5 cultures from each egg mass). Larvae in the survival culture of Set I were counted and examined at hatching, $40 \mathrm{~d}$ after hatching and subsequently on an irregular schedule. In Set II, larvae in survival cultures were counted and examined every $9 \mathrm{~d}$ for the first $54 \mathrm{~d}$ and then monthly. Larvae maintained for growth observations were sampled and weighed every $6 \mathrm{~d}$ for the first $54 \mathrm{~d}$ and monthly thereafter. In growth cultures, shell length (the longest shell dimension) of 10 larvae was measured at each sampling date. Larvae from each culture sampled for growth determinations were placed on filter paper that absorbed the small volume of sea water from around the hydrophobic shells of the veligers leaving them free of contaminating salts. The larvae were dried at $60^{\circ} \mathrm{C}$ and then transferred to preashed and pre-weighed ( $<2 \mathrm{mg}$ ) aluminium foil pans. They were then dried to constant mass at $80^{\circ} \mathrm{C}$ and mass determinations of 10 pans each containing larvae were made on each sampling date. The larvae in pans were next ashed at $500^{\circ} \mathrm{C}$ for $3 \mathrm{~h}$ and re-weighed. The $500^{\circ} \mathrm{C}$ temperature was used to prevent the decomposition of $\mathrm{CaCO}_{3}$ in the veliger shell that would occur at higher temperatures (Paine, 1964). Mass determinations were made on a Cahn 25 Automatic Electrobalance using the $2 \mathrm{mg}$ range. Ten pans, each containing 10 larvae, were weighed at hatching. Six d after hatching, 10 pans, each containing 5 larvae, were weighed. In Set I, 10 pans containing 3 larvae each were weighed $12 \mathrm{~d}$ after hatching. All other mass determinations consisted of 10 pans each containing 1 larva. During the weighing procedure, pans of larvae whose mass was not being determined were held at $\sim 80^{\circ} \mathrm{C}$ before ashing and $\sim 160^{\circ} \mathrm{C}$ after ashing to prevent absorption of atmospheric water vapor.

Larvae from growth and survival cultures were periodically tested for competence to metamorphose. In order to avoid depleting the number of larvae in the cultures only 5 or 10 larvae were used for each test. In 2 tests run on larvae from the stock cultures of Set II at 210 and $250 \mathrm{~d}$ after release from the egg mass, 28 and 23 larvae, respectively, were tested. In Set I, unmetamorphosed larvae were not returned to culture. In survival cultures of Set II, most unmetamorphosed larvae were returned to culture. Larvae that were tested for competence to metamorphose were placed in stender dishes containing Millipore pre-filtered sea water and either Ulva fasciata or U. reticulata, algae that can induce metamorphosis (Switzer-Dunlap and Hadfield, 1977). Cetyl alcohol (n-hexadecanol) was sprinkled on the water surface to prevent larvae from becoming immobilized by surface tension (Hurst, 1967). Larvae that gave rise to feeding juveniles were considered to have completed metamorphosis successfully.

Juveniles that metamorphosed from larvae obtained from the stock cultures at 210 and $250 \mathrm{~d}$ and from one of the survival cultures of Set II at $311 \mathrm{~d}$ were reared through reproductive maturity using the methods of Switzer-Dunlap and Hadfield (1979).

Both linear and log-linear regression analyses were performed on the data from the 3 survival cultures of Set II. At $174 \mathrm{~d}, 1$ of the 3 cultures was counted $1 \mathrm{~d}$ later, and at $204 \mathrm{~d}, 1$ culture was counted $3 \mathrm{~d}$ later. In each case, all 3 cultures were considered to be counted on the same day for the purpose of regression. All other cultures were counted on the days indicated.

\section{RESULTS}

Larvae of Aplysia juliana underwent a typical posthatching development (Switzer-Dunlap and Hadfield, 1977), increasing in maximum shell length from $\sim 130$ $\mu \mathrm{m}$ at hatching to a plateau of $\sim 335 \mu \mathrm{m}$. Other than the propodium of the larval foot, no development of organs preparatory for a benthic juvenile existence was 

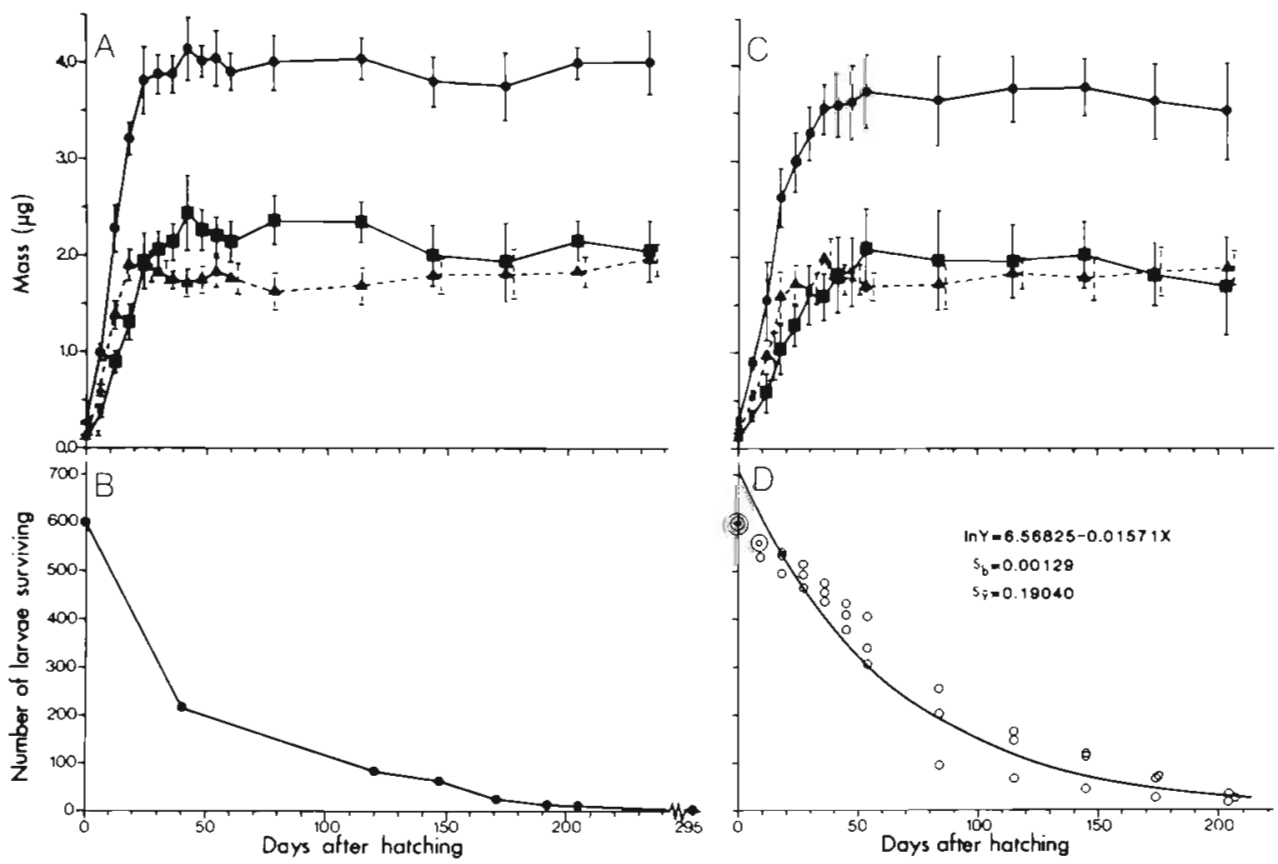

Fig. 1. Aplysia julianae Growth and survival during long-term larval culture. (A) and (B): growth and survival cultures of Set $\mathrm{I}$;

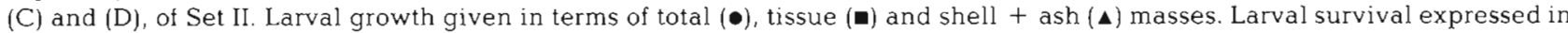
terms of number of larvae remaining alive at a given number of days after hatching. At each data point, means are given for (A) $\mathrm{n}=20$ mass determinations, 10 from each of 2 cultures; (C) $\mathrm{n}=30$ mass determinations, 10 from each of 3 cultures; except as follows: in (A) at $\mathrm{O}$ and $6 \mathrm{~d}, \mathrm{n}=10$ (larvae are representative of both cultures), in (C) at 30,42 , and $115 \mathrm{~d}, \mathrm{n}=29, \mathrm{at} 84 \mathrm{~d}, \mathrm{n}=28$ and at $204 \mathrm{~d}, \mathrm{n}=26$. Error bars are \pm 1 standard deviation. In Set I, growth and survival cultures were not run concurrently. Three larvae remained alive at $316 \mathrm{~d}$ after hatching in 1 survival culture of Set II

observed throughout the period of culture. Initial shell and tissue growth was essentially linear. Shell length and mass reached a plateau about $20 \mathrm{~d}$ after hatching. Total mass and tissue mass reached a plateau at about 36 and 54 d respectively in Sets I and II (Fig. 1). Tissue mass continued to increase for $16 \mathrm{~d}$ in Set I and $34 \mathrm{~d}$ in Set II after cessation of shell growth. Larvae, though continuing to feed and swim, entered a no-growth phase; tissue and shell mass reached a plateau and remained nearly constant up to $234 \mathrm{~d}$ after hatching, the longest period for which growth measurements were made. The only differences observed between larvae at the beginning of their growth plateau and after extended survival were the development of brown pigment deposits in the foot and retracted mantle fold, and a pink pigment accumulation at the rear of the mantle cavity.

Larvae in survival cultures developed normally and survived as long as $316 \mathrm{~d}$. Deviations from regression in the linear analysis performed on the survival data from Set II showed a significant $(p<0.005$ ) lack of fit. The regression curve calculated for log transformed data was significant at the $\mathrm{p}<0.025$ level and deviations from regression did not show significant lack of fit $(0.25>p>0.10)$. The regression curve and standard errors of the regression coefficient, $s_{b}$, and the intercept, $s_{y}$, are given in Fig. 1
Degeneration of larval organs, such as that described for the velum of larvae of the lamellabranch Mytilus edulis during long term culture (Bayne, 1965), did not occur. Aplysia juliana veligers rarely demonstrated the searching-crawling phase described for other molluscan larvae prior to metamorphosis (Thompson, 1958 , 1962; Bayne, 1965). Spontaneous metamorphosis was never observed.

The percentage of larvae completing metamorphosis in both young and old veligers that had undergone sufficient development to attain competence to metamorphose was generally low and varied from $0 \%$ to $60 \%$. In Set I, 3 larva out of 5 tested reached the feeding juvenile stage $173 \mathrm{~d}$ after hatching. In Set II, 2 larvae out of 28 at 210 d, 2 larvae out of 23 at $250 \mathrm{~d}$, and 1 larva out of 5 at 311 d developed into feeding juveniles. These juveniles appeared normal and those from Set II underwent typical growth (Switzer-Dunlap and Hadfield, 1977, 1979) through reproductive maturity.

\section{DISCUSSION AND CONCLUSIONS}

As larvae of Aplysia juliana reared in laboratory culture complete their development and become competent to metamorphose they enter into a 'delay' 
period (Scheltema, 1967) characterized by a non-growing state, like that described by Scheltema (1966). This no-growth stage can be sustained for long periods of time, and Pechenik (1980) has suggested that it could be accomplished by a decrease in either the rate of ingestion or assimilation efficiency, an increase in the rate of energy demand relative to energy accumulation, or any combination of these. The accumulation of brown pigment in the larval foot and retracted mantle fold during extended larval survival is reminiscent of lipofuscin deposition in cells of senescing higher organisms (Strehler, 1964) and suggests that not all larval metabolic processes attain a steady state. The logarithmic survival curve, however, implies that larval mortality is due to extrinsic environmental factors rather than senescence (Comfort, 1979). Bacterial contamination is known to affect viability of lamellibranch larvae in culture (Walne, 1958; Guillard, 1959) and despite the addition of antibiotics may have influenced larval mortality in cultures of $A$. juliana. In addition, the large range of temperature variation experienced in the laboratory may have had an adverse effect on larval survival.

An important factor affecting the potential of a larva to achieve long-distance dispersal is its capacity to maintain the ability to metamorphose for long periods of time. Many invertebrate larvae appear to possess the potential to maintain metamorphic competence in that they show a preference to metamorphose only in response to a specific substrate (Thompson, 1958, 1962; Hadfield and Karlson, 1969; Kriegstein et al., 1974; Harris, 1975; Hadfield, 1977; Kempf and Willows, 1977; Perron and Tumer, 1977; Switzer-Dunlap and Hadfield, 1977; Chia and Koss, 1978; Chia and Rice, 1978). In some instances, as the duration of larval life increases, larvae become less discriminating and eventually may undergo spontaneous metamorphosis (Thorson, 1966; Pechenik, 1980). Larvae of Aplysia juliana cultured in the laboratory are typically competent to metamorphose $28 \mathrm{~d}$ after emerging from the egg mass (Switzer-Dunlap and Hadfield, 1977). Even during periods of culture as long as $311 \mathrm{~d}$, spontaneous metamorphosis was not observed and larvae continued to metamorphose only in response to Ulva. While larvae in long-term cultures varied in their ability to metamorphose (0-60\%) when tested periodically, the differences were no greater than those observed in young larvae that have recently attained metamorphic competence (Switzer-Dunlap, pers. comm.). The observed variation did not correlate with larval age and was assumed to be caused by inadequate culture conditions. The important result of the tests for metamorphic competence is that some larvae were capable of completing metamorphosis and of growing to reproductive maturity even after 210,250 and $311 \mathrm{~d}$ in culture. Thus, the larvae of $A$ juliana have the potential to maintain competence to metamorphose during periods of teleplanic dispersal. If oceanic waters provide more optimal conditions for sustaining larvae than closed laboratory systems, survival and competence to metamorphose should be more readily maintained in the natural environment.

A number of observations indicate that larvae of Aplysia juliana, and probably some other opisthobranchs as well, do accomplish long-distance dispersal. Adult A. juliana have a world-wide tropical distribution and are also found in the colder waters of Japan (Eales, 1960; Marcus, 1972). Opisthobranch larvae have been found in plankton tows up to 500 miles from shore (Mileikovsky, 1968), a distance more than sufficient to place them in major ocean currents. A. juliana reared in the laboratory can each produce as many as $2.72 \times 10^{8}$ eggs during their lifetime (Swither-Dunlap and Hadfield, 1979). Densities in field populations may be as high as 3.5 animals $-\mathrm{m}^{-2}$ and spawn production may reach $6.56 \times 10^{6}$ eggs $-\left(\mathrm{m}^{2}\right.$ wk $)^{-1}$ (Sarver, 1978). The large numbers of larvae emerging from these egg masses increase the chance that some veligers avoid predation or mortality from other environmental factors during extended periods adrift in the plankton. In addition to long survival and maintenance of competence to metamorphose that is observed in the laboratory, the distribution of the adults and the fecundity of the species support the hypothesis that larvae of A. juliana have a potential for long-distance dispersal.

Thorson (1961) estimated that transport by ocean currents from Japan to Mellish Bank (near the northwest extension of the Hawaiian archipelago) would take $77 \mathrm{~d}$. This period is well within the survival capabilities of larvae of Aplysia juliana and may explain the means by which its original invasion of these islands was accomplished, as well as how this species can continue to maintain genetic relationship with conspecifics in remote areas. Accumulating evidence for teleplanic larvae presented here and elsewhere (Scheltema, 1966, 1971a, b; Strathman, 1978) supports the hypothesis that this means of dispersal and subsequent genetic interchange is of more importance in species distribution and prevention of speciation than previously thought.

Acknowledgements. I wish to thank Drs. M. Switzer-Dunlap, J. M. Arnold, D. B. Bonar, J. Archie, particularly M. G. Hadfield and anonymous reviewers (even the lone dissenter) for discussions and reviews that greatly improved the quality of this paper. R. I. Kempf provided encouragement and grammatical advice. This research was supported by National Institutes of Health grant RR01057 to M. G. Hadfield and a grant from the Hawarian Malacological Society to S. C. Kempf. 


\section{LITERATURE CITED}

Bayne, B. L. (1965). Growth and the delay of metamorphosis of the larvae of Mytilus edulis (L.). Ophelia 2: 1-47

Chia, F. S., Koss, R. (1978). Development and metamorphosis of the planktotrophic larvae of Rostanga pulchra (Mollusca: Nudibranchia). Mar. Biol. 46: 109-119

Chia, F. S., Rice, M. E. (eds.) (1978). Settlement and metamorphosis of marine invertebrate larvae. Elsevier, New York

Comfort, A. (1979). The biology of senescence 3rd ed. Elsevier, New York

Eales, N. B. (1960). Revision of the world species of Aplysia (Gastropoda, Opisthobranchia). Bull. Br. Mus, nat. Hist. Zool. 5: 267-400

Ekman, S. (1953). Zoogeography of the sea, Sedgewick and Jackson, Ltd., London

Guillard, R. R. L. (1959). Further evidence of the destruction of bivalve larvae by bacteria. Biol. Bull. mar biol. Lab., Woods Hole 117: 258-266

Hadfield, M. G. (1963). The biology of nudibranch larvae. Oikos 14: 85-95

Hadfield, M. G. (1977). Chemical interactions in larval settling of a marine gastropod. In: Faulkner, D. J., Fenical, W. H. (eds.) Marine natural products chemistry. Plenum Publishing Corporation, New York, pp. 403-413

Hadfield, M. G., Karlson, R. H. (1969). Externally induced metamorphosis in a marine gastropod. Am, Zool. 9: 317

Harris, G. L. (1975). Studies on the life history of two coraleating nudibranchs of the genus Phestilla. Biol. Bull. mar. biol. Lab., Woods Hole 149: 539-550

Hurst, A. (1967). The egg masses and veligers of thirty northeast Pacific opisthobranchs. Veliger 9: 255-288

Kempf, S. C., Willows, A. O. D. (1977). Laboratory culture of the nudibranch Tritonia diomedea Bergh (Tritoniidae: Opisthobranchia) and some aspects of its behavioral development. J. exp. mar. Biol. Ecol. 30: 261-276

Kriegstein, A. R., Castellucci, V., Kandel, E. R. (1974) Metamorphosis of Aplysia californica in laboratory culture. Proc. natn. Acad. Sci. U.S.A. 22: 3654-3658

Marcus, E. B.-R. (1972). On the Anaspidea (Gastropoda: Opisthobranchia) of the warm waters of the western Atlantic. Bull. mar. Sci. 22: 267-404

Mileikovsky, S. A. (1968). Some common features in the drift of pelagic juvenile and larval stages of bottom invertebrates with marine currents in temperate regions. Sarsia 34: 209-216

Paine, R. T. (1964). Ash and calorie determinations of sponge and opisthobranch tissues. Ecology 45: 384-387

Pechenik, J. A. (1980). Growth and energy balance during the larval lives of three prosobranch gastropods. J. exp. mar. Biol. Ecol. 44: 1-28

Perron, F. E., Tumer, R. D. (1977). The development, metamorphosis and natural history of the nudibranch
Doridella obscura Verrill (Corambidae: Opisthobranchia). J. exp. mar. Biol. Ecol. 30: 171-185

Sarver, D. J. (1978). The ecology and energetics of Aplysia juliana (Quoy and Quaimard, 1832). Ph. D. dissertation, University of Hawaii, Honolulu

Scheltema, R. S. (1966). Evidence for trans-Atlantic transport of gastropod larvae belonging to the genus Cymatium Deep Sea Res. 13: 83-95

Scheltema, R. S. (1967). The relationship of temperature to the larval development of Nassarius obsoletus (Gastropoda). Biol. Bull. mar biol. Lab., Woods Hole 132: 253-265

Scheltema, R. S. (1971a). Larval dispersal as a means of genetic exchance between geographically separated populations of shallow-water benthic marine gastropods. Biol. Bull. mar. biol. Lab., Woods Hole 140: 284-322

Scheltema, R. S. (1971b). The dispersal of larvae of shoalwater benthic invertebrate species over long distances by ocean currents. In: Crisp, D. J. (ed.) Fourth European Marine Biology Symposium. Cambridge University Press, Cambridge, pp. 7-28

Strathman, R. (1978). Length of pelagic period in echinoderms with feeding larvae from the northeast Pacific. J. exp. mar. Biol. Ecol. 34: 23-27

Strehler, B. L. (1964). On the histology and ultrastructure of age pigment. In: Strehler, B. (ed.) Advances in gerontological research, Vol. 1. Academic Press, New York, pp. 343-384

Switzer-Dunlap, M., Hadfield, M. G. (1977). Observations on development, larval growth and metamorphosis of four species of Aplysiidae (Gastropoda, Opisthobranchia) in laboratory culture. J. exp. mar. Biol. Ecol. 29: 245-261

Switzer-Dunlap, M., Hadfield, M. G. (1979). Reproductive patterns of Hawaiian Aplysiid gastropods. In: Stancyk, S. E. (ed.) Reproductive ecology of marine invertebrates. University of South Carolina Press, Columbia, pp. 199-210

Thompson, T E. (1958). The natural history, embryology, larval biology and post-larval development of Adalaria proxima (Alder and Hancock) (Gastropoda, Opisthobranchia). Phil. Trans. R. Soc. (B) 242: 1-58

Thompson, T. E. (1962). Studies on the ontogeny of Tritonia hombergi Cuvier (Opisthobranchia). Phil. Trans. R. Soc (B) $245: 171-218$

Thorson, G. (1950). Reproductive and larval ecology of marine bottom invertebrates. Biol. Rev. 25: 1-45

Thorson, G. (1961). Length of pelagic larval life in marine bottom invertebrates as related to larval transport by ocean currents. In: Sears, M. (ed.) Oceanography. American Association for the Advancement of Science, Washington D. C., pp. 455-474

Thorson, G. (1966). Some factors influencing the recruitment and establishment of marine benthic communities. Neth. J. Sea Res. 3: 267-293

Walne, P. R. (1958). The importance of bacteria in laboratory experiments on rearing the larvae of Ostrea edulis. J. mar biol. Ass. U. K. 37: 415-425 